\title{
A utilização de software educativo pelos professores de Química e de Física
}

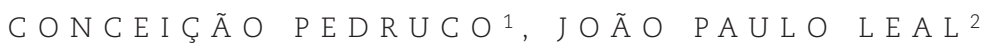

A sociedade actual caracteriza-se por ser uma sociedade em rápida mudança, em que a actualização constante dos conhecimentos é uma necessidade de primeira ordem. Esta actualização só se torna possível através da utilização das novas Tecnologias de Informação e Comunicação, nomeadamente na escola.

$\mathrm{Na}$ sala de aula o computador ganha um novo espaço, em que a utilização de software educativo abre novas possibilidades, rompendo com o processo tradicional de ensino e de aprendizagem. Em Portugal, e no caso específico da Química e da Física, parece haver ainda alguma resistência à introdução destas novas práticas educativas, mas, ao mesmo tempo, surgem indícios encorajadores de mudanças de atitude.

O presente artigo apresenta resultados obtidos num estudo realizado no âmbito de uma tese de Mestrado em Química para o Ensino, na Universidade de Lisboa, que pretendeu conhecer a utilização de software educativo pelos professores de Química e de Física a leccionar em escolas de Portugal (à excepção das escolas pertencentes às regiões do Grande Porto e da Grande Lisboa).

\section{Introdução}

A sociedade actual exige mudanças. Tudo deve ser revisto, até a forma de ensinar e de aprender. Com efeito, a sociedade actual, uma Sociedade de Informação, conta com uma rápida evolução e difusão de novas tecnologias, que incidem de maneira significativa em todos os níveis do mundo educativo, obrigando-o a fazer mudanças. As novas tecnologias, nomeadamente aquelas que estão associadas ao computador e ao software educativo, podem favorecer a aplicação de pedagogias activas, contribuir para um ensino de melhor qualidade e desempenhar um papel de mudança.

Para o efeito, é necessário, por um lado, familiarizar os professores e os alunos com essas tecnologias e, por outro, efectuar um investimento na formação

\footnotetext{
1 Professora da Escola Secundária de Gama Barros, 2735-473 Cacém conceicaopedrucoesgb@iol.pt

2 Departamento de Química, Instituto Tecnológico e Nuclear, 2686-953 Sacavém e Departamento de Química e Bioquímica, Faculdade de Ciências, Universidade de Lisboa, 1049-016 Lisboa

jpleal@itn.pt
}

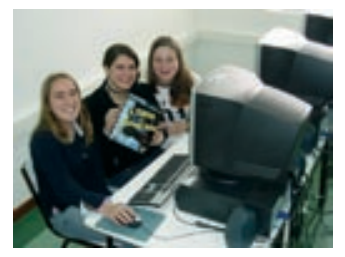

Figura 1 Ambiente de boa disposição numa aula de (FQ) Físico-Química, com utilização de software educativo.

de professores, de forma a prepará-los para a Sociedade de Informação. Apesar de parecer ser inquestionável o facto de o software educativo poder responder a muitos dos problemas que emergem do processo de ensino e de aprendizagem, nomeadamente das ciências, não é ainda conhecida a realidade nacional sobre a utilização desta ferramenta em contexto educativo, por parte de professores de Química e de Física.

O objectivo deste estudo foi verificar se os professores de Química e de Física utilizam, ou não, software educativo em contexto escolar, qual o grau desta prática, como é que os professores a entendiam, como é que calculavam os seus benefícios e qual era o balanço que faziam dessa actividade; e, se ao utilizarem, conseguem nos seus alunos, para além de sorrisos e boa disposição (Figura 1), algo mais, nomeadamente o aumento do aproveitamento e do interesse na disciplina.

\section{Metodologia}

Este estudo incidiu nos professores de Química e de Física a leccionar em escolas de Portugal, à excepção das escolas do Grande Porto e da Grande Lisboa e decorreu em duas fases. A primeira consistiu na aplicação de um questionário on-line. Construiu-se uma página na Internet para a divulgação do estudo, colocou-se o questionário on-line nessa página e o seu endereço foi enviado a uma amostra de 997 escolas. O período de recolha de informação decorreu entre 1 de Março de 2004 e 1 de Março de 2005. Com esta metodologia recolheram-se on-line 97 respostas de docentes de 77 estabelecimentos de ensino (Tabela 1).

Na segunda fase realizaram-se entrevistas a dois respondentes do questionário, utilizadores de software educativo, pro- 
Tabela 1 Número de respostas dos professores por distrito/região da escola onde leccionam.

fessores da EB 2,3 Padre Abílio Mendes, em Setúbal.

\section{Resultados}

A análise das respostas ao questionário permitiu concluir que a maioria dos respondentes (65\%) é utilizadora de software educativo (SE). Permitiu também traçar uma imagem do respondente tipo que é do género feminino, com idade compreendida entre os 26 e os 35 anos, profissionalizado, com menos de 6 anos de serviço, e com componente lectiva.

No que se refere aos programas informáticos utilizados pelos professores da amostra pode-se observar (Figura 2) que os mais utilizados pelos professores da amostra são "O sapo explica...Ciências Físico-Naturais - A Terra no Espaço 3. ${ }^{\circ}$ ciclo" (73\%), a "Tabela Periódica" (67\%), "O Professor Teles Cópio... A Terra e o Sistema Solar" (63\%) e a "Diciopédia" (56\%). Qualquer destes programas é usado por mais de metade dos professores que usam software educacional o que mostra a sua penetração junto da comunidade escolar. No extremo oposto, com apenas $2 \%$ de utilização surgem os programas "RLC" e "Genial - O grande jogo da sabedoria".

Analisando a utilização por áreas dentro da Química e da Física (Figura 3) as mais representadas são a Astronomia (45\%) e a Tabela Periódica (42\%). Por outro lado, as menos representadas são as áreas da Mudança Global (3\%), da Atmosfera e Mudanças de Temperatura (4\%) e da Termodinâmica (5\%). No que diz respeito às actividades realizadas no laboratório, é na área da Química que os professores da amostra mais utilizam software educativo (25\%); na Física apenas $18 \%$ o usam. Cerca de $24 \%$ dos professores da amostra utilizam software educativo numa área muito importante que é a área da Segurança no Laboratório.

Fez-se também um levantamento da utilização do software em função do ano de escolaridade e, quando aplicável, em função da disciplina (Figura 4). Verifica-se que os maiores valores percentuais

\begin{tabular}{|c|c|c|}
\hline Distrito/Regiâo da escola & Nome da escola & $\mathrm{N} .^{\circ}$ de respostas \\
\hline \multirow[t]{7}{*}{ Lisboa } & EB 2,3 de Freiria & 2 \\
\hline & EB 2,3 de São Gonçalo & 1 \\
\hline & EB 2,3 Dr. JoÃo das Regras & 1 \\
\hline & EBI do Carregado & 1 \\
\hline & ES da Lourinhã & 1 \\
\hline & ES/EB3 de Madeira Torres & 1 \\
\hline & & 7 \\
\hline \multirow[t]{6}{*}{ Vila Real } & Colégio Nossa Senhora da Boavista & 1 \\
\hline & EB 2,3 José dos Anjos & 3 \\
\hline & ES Dr. António Granjo & 1 \\
\hline & ES/EB3 do Baixo Barroso & 1 \\
\hline & Escola desconhecida & 2 \\
\hline & & 8 \\
\hline \multirow[t]{4}{*}{ Viana do Castelo } & Ancorensis Cooperativa de Ensino & 3 \\
\hline & ES de Monserrate & 1 \\
\hline & ES/EB3 de Barroselas & 2 \\
\hline & & 6 \\
\hline \multirow[t]{2}{*}{ Viseu } & EB 2,3 de Ferreira de Aves & 1 \\
\hline & & 1 \\
\hline \multirow[t]{5}{*}{ Porto } & EB 2,3 Caide Rei & 1 \\
\hline & EB 2,3 de Lagares & 1 \\
\hline & EB 2,3 de Sande & 1 \\
\hline & ES D. Diniz & 1 \\
\hline & & 4 \\
\hline \multirow[t]{8}{*}{ Setúbal } & EB 2,3 Padre Abilio Mendes & 2 \\
\hline & EB 2,3 Quinta Nova da Telha & 1 \\
\hline & ES Augusto Cabrita & 2 \\
\hline & ES Dom Manuel Martins & 1 \\
\hline & ES/EB3 Anselmo Andrade & 1 \\
\hline & ES/EB3 EI Rei D. Manuel I & 2 \\
\hline & Escola desconhecida & 1 \\
\hline & & 10 \\
\hline \multirow[t]{2}{*}{ Portalegre } & ES de São Lourenço & 4 \\
\hline & & 4 \\
\hline \multirow[t]{3}{*}{ Beja } & EB 2,3 Damião de Odemira & 1 \\
\hline & EB 2,3 Eng. Manuel Rafael Amaro da Costa & 2 \\
\hline & & 3 \\
\hline \multirow[t]{7}{*}{ Santarém } & EB 2,3 D. Manuel I & 1 \\
\hline & EB 2,3 Manuel de Figueiredo & 1 \\
\hline & ES de Jâcome Ratton & 1 \\
\hline & ES Dr. Augusto César da Silva Ferreira & 1 \\
\hline & ES/EB3 de Luís de Camões & 1 \\
\hline & ES/EB3 de Mação & 1 \\
\hline & & 6 \\
\hline \multirow[t]{6}{*}{ Guarda } & EB 2,3 da Guarda - Sequeira & 1 \\
\hline & E.B 2,3 de Manteigas & 1 \\
\hline & EB 2,3 Dr. Guilherme Correia de Carvalho & 1 \\
\hline & ES/EB3 de Fornos de Algodres & 1 \\
\hline & Externato Evaristo Nogueira & 2 \\
\hline & & 6 \\
\hline \multirow[t]{6}{*}{ Faro } & EB 2,3 D. Dinis & 2 \\
\hline & EB 2,3 de Ferreiras & 1 \\
\hline & EB 2,3 José Carlos da Maia & 1 \\
\hline & ES de Manuel Teixeira Gomes & 1 \\
\hline & ES Júlio Dantas de Lagos & 1 \\
\hline & & 6 \\
\hline \multirow[t]{11}{*}{ Aveiro } & Colégio de Nossa Senhora da Assunção & 1 \\
\hline & EB 2,3 de Canedo & 1 \\
\hline & EB 2,3 de Carregosa & 1 \\
\hline & EB 2,3 de Florbela Espanca & 1 \\
\hline & EB 2,3 de Sever do Vouga & 1 \\
\hline & EB 2,3 de Vilarinho do Bairro & 1 \\
\hline & EB 2,3 Dr. João Rocha-Pai & 2 \\
\hline & EB 2,3 Fernando Caldeira & 2 \\
\hline & ES de Castelo de Paiva & 1 \\
\hline & ES/EB3 de Vagos & 1 \\
\hline & & 12 \\
\hline
\end{tabular}




\begin{tabular}{|c|c|c|}
\hline Distrito/Região da escola & Nome da escola & $\mathrm{N} .{ }^{\circ}$ de respostas \\
\hline \multirow[t]{3}{*}{ Leiria } & EB 2,3 Frei Estevão Martins & 1 \\
\hline & EBI/JI de Santa Catarina & 1 \\
\hline & & 2 \\
\hline \multirow[t]{2}{*}{ Bragança } & ES Abade de Baçal & 1 \\
\hline & & 1 \\
\hline \multirow[t]{5}{*}{ Braga } & EB 2,3 de Celeirós & 1 \\
\hline & EB 2,3 de Silvares & 1 \\
\hline & ES/EB3 da Veiga & 1 \\
\hline & ES/EB3 de Vieira do Minho & 1 \\
\hline & & 4 \\
\hline \multirow[t]{3}{*}{ Castelo Branco } & EB 2,3 de Paúl & 1 \\
\hline & EB Serra da Gardunha & 1 \\
\hline & & 2 \\
\hline \multirow[t]{4}{*}{ Coimbra } & Centro de Estudos Educativos de Ançã & 1 \\
\hline & EB 2,3 Dr." Maria Alice Gouveia & 1 \\
\hline & ES de Cantanhede & 1 \\
\hline & & 3 \\
\hline \multirow[t]{4}{*}{ Évora } & EB 2,3 Padre Bento Pereira & 1 \\
\hline & ES/EB3 de Cunha Rivara & 1 \\
\hline & ES/EB3 de Mora & 1 \\
\hline & & 3 \\
\hline \multirow[t]{5}{*}{ R. A. Madeira } & EB 2,3 Dr. Horácio Bento de Gouveia & 3 \\
\hline & ES Francisco Franco & 1 \\
\hline & ES/EB 3 Dr. Ângelo A. Silva & 1 \\
\hline & ES/EB3 de Machico & 1 \\
\hline & & 6 \\
\hline \multirow[t]{4}{*}{ R. A. Açores } & BI de Ginetes & 1 \\
\hline & ES Jerónimo Emiliano de Andrade & 1 \\
\hline & ES/EB3 das Laranjeiras & 1 \\
\hline & & 3 \\
\hline
\end{tabular}

se situam no ensino básico na disciplina de Físico-Química. No secundário essa mesma utilização está dispersa por mais de uma disciplina, mas em nenhuma delas se atingem valores próximos dos obtidos para Físico-Química.

Um dos pontos mais importantes deste estudo era perceber o modo como a utilização de software educativo se repercutia nos alunos. A maioria dos utilizadores de software educativo detectou um aumento no aproveitamento dos alunos na disciplina (68\%), na orientação e ajuda recíproca dos alunos (79\%) e no interesse pela disciplina (95\%) (Figura 5). Uma percentagem muito reduzida da amostra observou uma redução, existindo nos dois primeiros critérios percentagens significativas de alunos que não mostraram alteração com a introdução desta abordagem.

Um outro factor relevante é a opinião dos professores sobre a utilização de software educativo. $72 \%$ e $53 \%$ dos professores da amostra consideram, respectivamente, que o tempo despendido e a facilidade na preparação das aulas aumentaram em consequência da utilização de software educativo (Figura 6).

No que se refere a atitudes negativas é interessante verificar (Figura 7) que a grande maioria dos professores da amostra não utilizadora de software educativo (76\%), não o considera apropriado para o ensino; sendo esta opinião de apenas $24 \%$ nos professores que utilizam software educativo. De igual modo $68 \%$ dos professores não utilizadores não conhecem a fundo as vantagens pedagógicas desta ferramenta; descendo este número para $40 \%$ nos que utilizam. Também, cerca de 50\% dos professores da amostra não utilizadores, consideram não dispor de conhecimentos/aptidões para utilizarem o software educativo, descendo este número para $13 \%$ junto daqueles que efectivamente usam SE. Curioso é verificar que existe um número razoável dos professores da amostra, quer sejam utilizadores (37\%), quer não (35\%), que consideram que os seus alunos, em muitos casos, dominam o computador melhor do que eles.
Finalmente $41 \%$ dos professores não utilizadores e $37 \%$ dos utilizadores sentem dificuldade em integrar o software educativo na sua prática de ensino, mas apenas $6 \%$ e $2 \%$, respectivamente, consideram que a sua utilização é uma perda de tempo.

Nas atitudes positivas a opinião de todos os professores da amostra (Figura 8) não mostra uma diferença significativa entre os que usam e os que não usam SE. É quase unânime no que respeita ao facto de gostar de aprender mais sobre software educativo, (94\% e 92\%, respectivamente para os não utilizadores e utilizadores de SE). Em todas as outras respostas os utilizadores de SE apresentam uma percentagem superior aos não utilizadores, mas a tendência é muito semelhante em ambos os grupos. Realçam-se aqui os valores para os professores utilizadores: 68\% considera que a formação em software educativo deveria ser obrigatória, 78\% afirma que o uso de software educativo estimula a criatividade dos alunos, 92\% reconhece que o uso de software educativo exige novas competências ao professor, 76\% considera que esta utilização encoraja os alunos a trabalhar em colaboração e, ainda, a ensinar com mais eficácia, $86 \%$ diz que o uso de software educativo ajuda os alunos a adquirir conhecimentos novos e efectivos e $94 \%$ afirma que esta utilização torna as aulas mais motivantes.

Muitas das atitudes atrás expressas, em especial as negativas, podem ser entendidas em função dos problemas que os professores enfrentam na utilização de software educativo (Figura 9). Os mais representativos são a insuficiência do número de computadores disponíveis, a falta de variedade de software educativo, a falta de informação sobre software educativo, dificuldades de acesso aos computadores existentes e limitações dos próprios computadores. Como se pode verificar pela Figura 10, apesar de grande parte dos respondentes possuir nas suas escolas computadores com processadores pentium IV e o sistema operativo windows $\mathrm{XP}$, ainda existem muitas escolas com computadores e sistemas operativos desactualizados. 


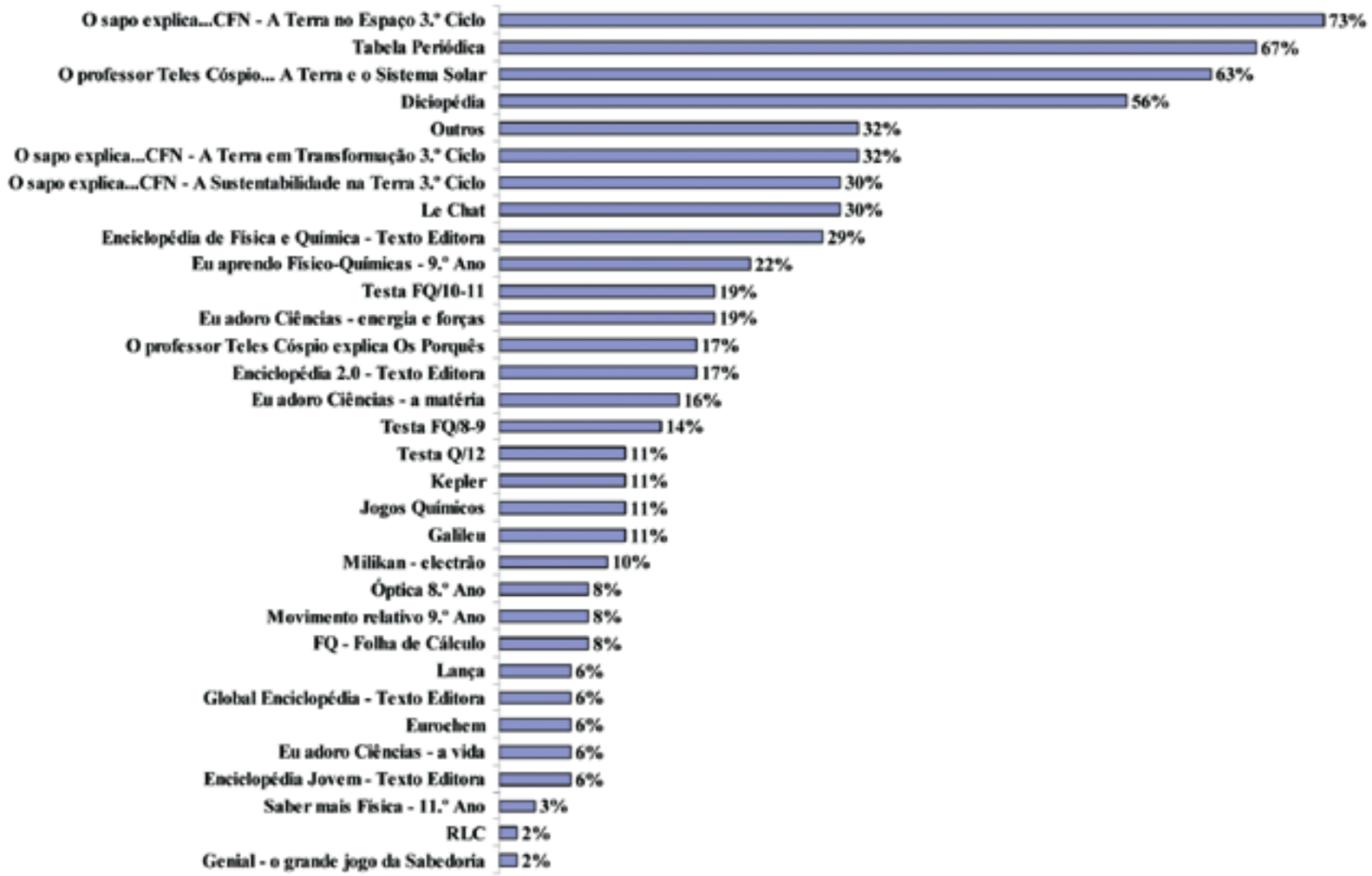

Figura 2 Utilização de software educacional em sala de aula pelos professores da amostra.

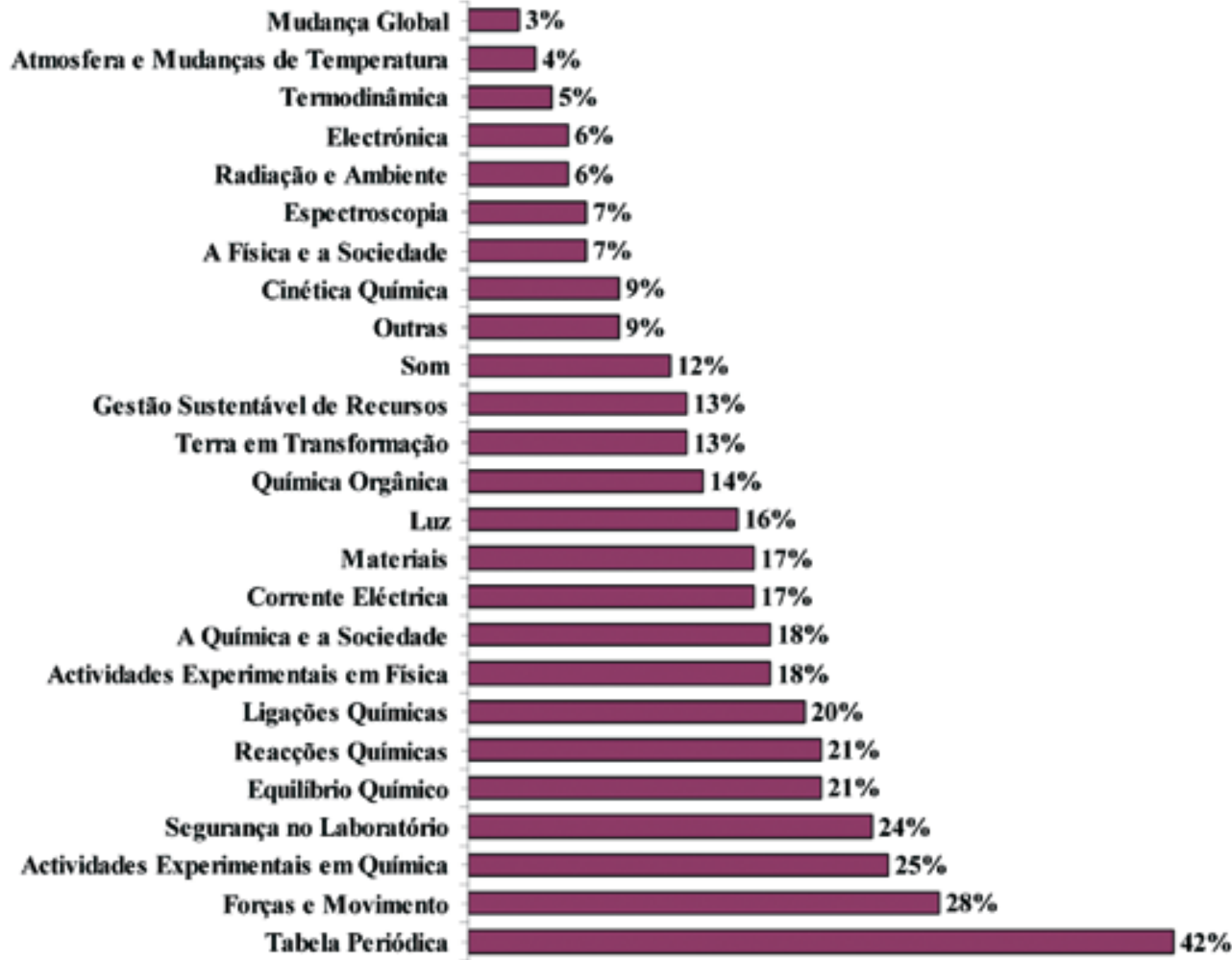

Figura 3 Áreas da Química e da Física escolhidas pelos professores para serem abordadas nas aulas com utilização de software educativo. 

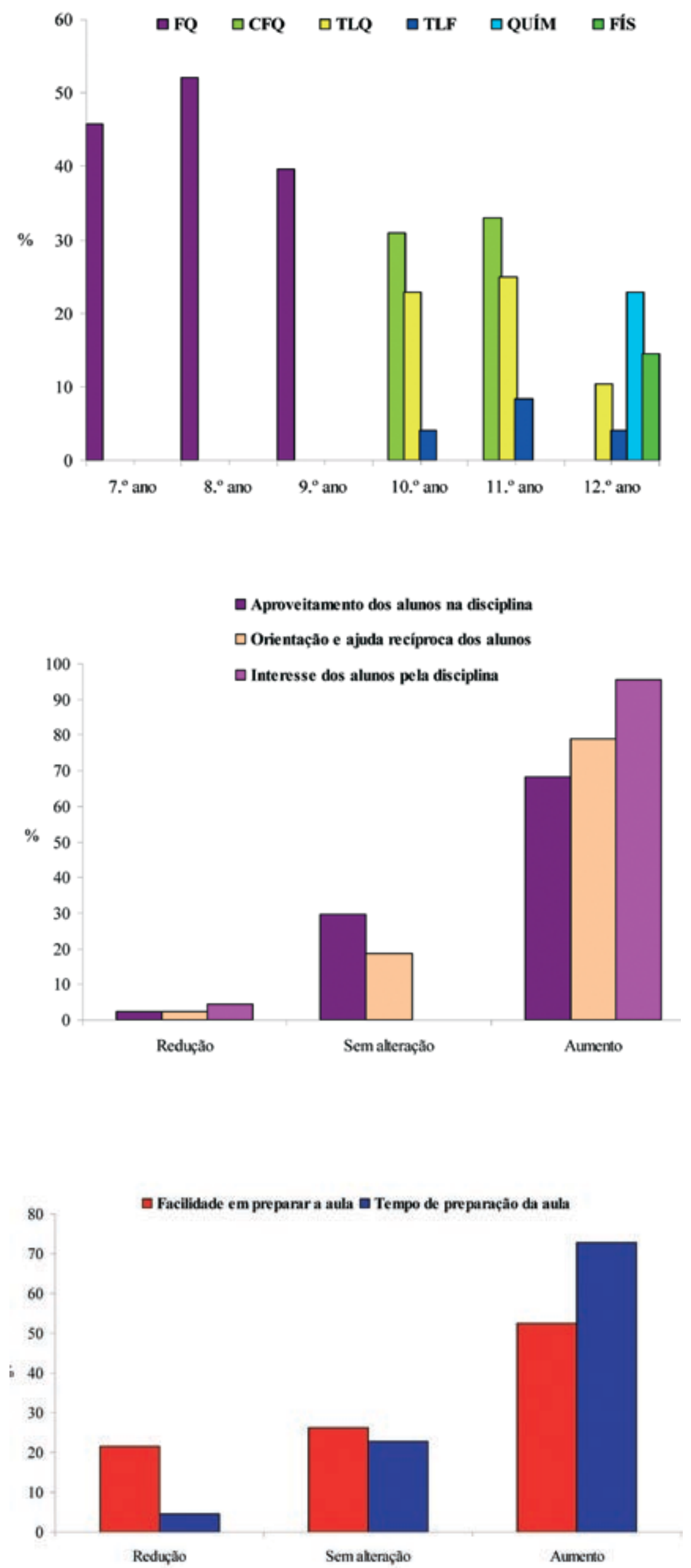

Figura 4 Distribuição percentual da frequência de utilização de software educativo por disciplina e por ano de escolaridade (FQ - Físico-Química; CFQ - Ciências FísicoQuímicas; TLQ - Técnicas Laboratoriais de Química; TLF - Técnicas Laboratoriais de Física; QUíM - Química; FÍS - Física).
Figura 5 Grau de alteração observado nos alunos em consequência da utilização de software educativo segundo os professores da amostra.
Figura 6 Grau de alteração observado na preparação das aulas em consequência da utilização de software educativo segundo os professores da amostra. 


\section{Entrevistas}

Foram entrevistados dois professores da escola EB 2,3 Padre Abílio Mendes. Estes professores são utilizadores de software educativo e faziam parte dos respondentes ao questionário disponível na Internet. Nas entrevistas confirmaram-se algumas das posições defendidas pelos respondentes: a novidade desta prática é um factor de motivação, mas também de indisciplina; a necessidade de existir uma consolidação da "matéria" abordada nessas aulas; a escola, nomeadamente os professores, oferecem uma grande resistência à novidade e a necessidade de potenciar estas novas práticas pelo trabalho em grupo por parte dos professores. Apresentam-se de seguida algumas transcrições que evidenciam as opiniões mani-

\section{Não utilizador $\square$ Utilizador}

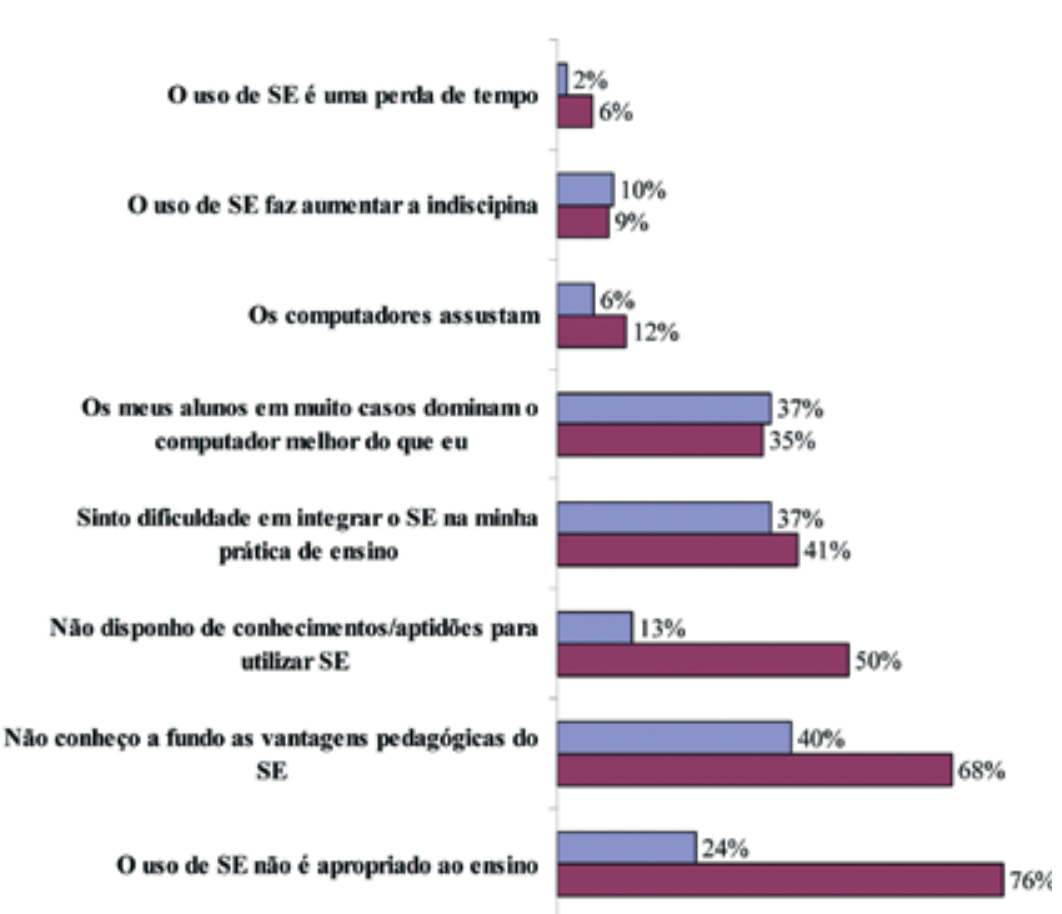

de software educativo com os alunos por parte dos professores da amostra, utilizadores e não utilizadores de software educativo.

— Não utilizador $\square$ Utilizador

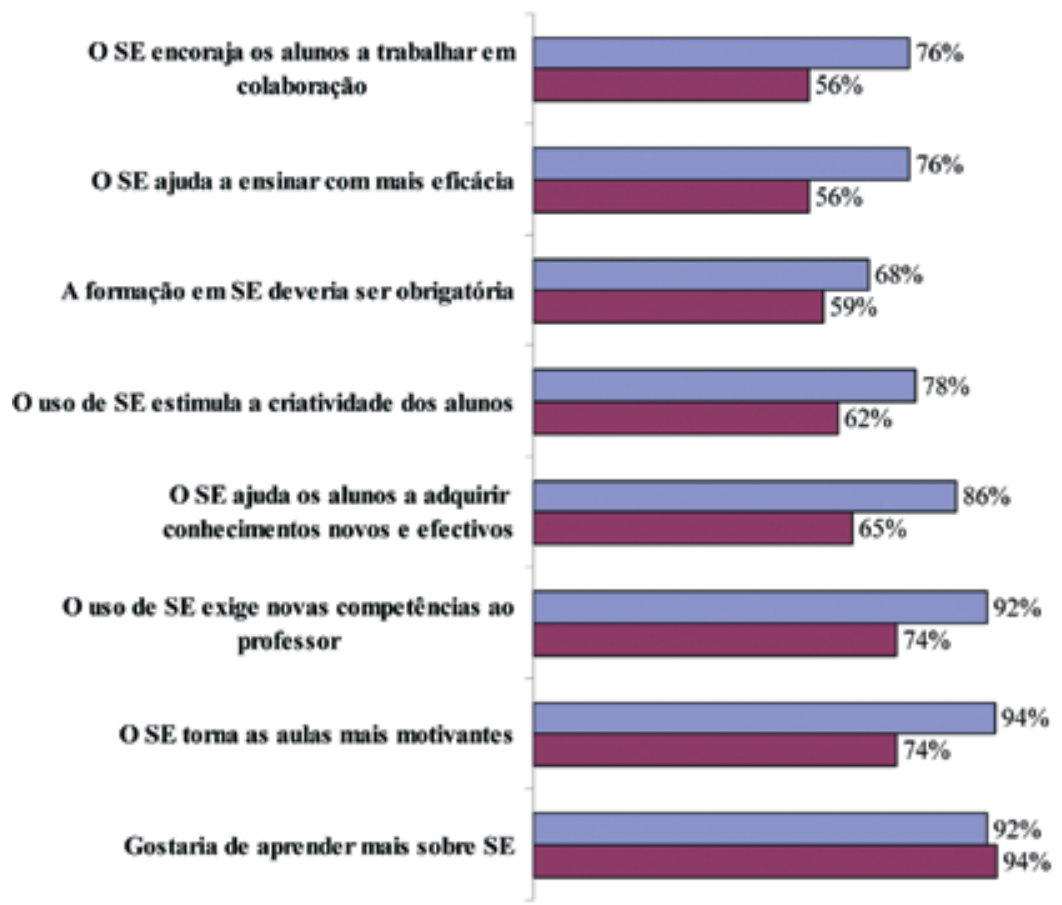



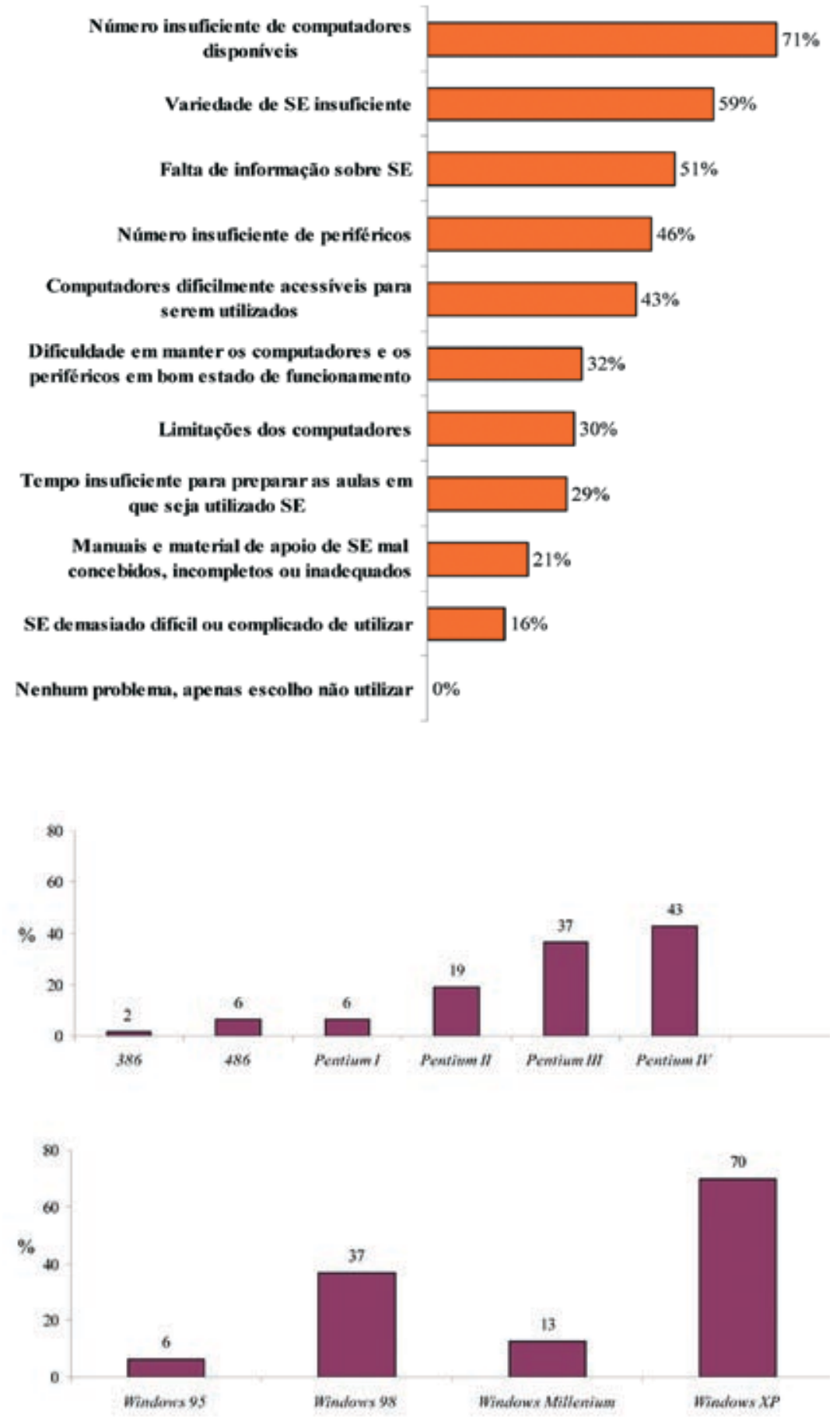

Figura 9 Problemas que os professores enfrentam no que respeita à utilização de software educativo.
Figura 10 Caracterização do parque informático (processadores e sistemas operativos) das escolas dos professores respondentes. festadas pelos professores durante as entrevistas:

“...os alunos percebem melhor, mas depois é preciso haver uma aula para eles passarem tudo para o caderno, porque senão não fica lá nada." "...os alunos ficam muito mais motivados." "...os alunos ficam mais curiosos." "...no computador é mais visível." "...uma coisa é pegar num livrinho...com uma fotografia, deste tamanho, explicar-Ihes como são os planetas..." “...outra coisa, é ver uma imagem no computador, grande com detalhe..." “...o computador permite fazer coisas que não se podem fazer no quadro." "...é muito mais interessante do que estar a olhar para um livro." "...é uma estratégia que ainda é pouco utilizada, por isso os miúdos gostam." "Os alunos ainda não reconhecem este tipo de aulas como sendo as "normais"." "...como é uma coisa nova, eles (os alunos) sentem liberdade... leva a uma certa indisciplina." "...não se trabalha em grupo, apesar de esta reorganização apontar nesse sentido."

\section{Conclusões}

As amostragens realizadas podem ser consideradas amostragens por conveniência (os respondentes podem não 
reflectir o conjunto de professores de Química e de Física), por isso se recomenda algum cuidado na generalização das conclusões à totalidade do universo dos docentes de Química e de Física. Contudo, pensa-se que se podem colher informações importantes e pertinentes no âmbito deste estudo.

Desde logo resulta a convicção de que é ainda moderado o entusiasmo dos professores na utilização de software educativo; que a prática destas aulas, por um lado, está associada à necessidade de haver um reforço das aprendizagens e, por outro, estas aulas são encaradas pelos alunos como sendo uma novidade, mas não como uma fonte de aquisição de aprendizagens. Há sempre uma grande resistência à mudança, e a escola não foge a esta regra. No entanto $65 \%$ dos professores respondentes usa SE nas suas aulas, sendo utilizados mais de 30 programas diferentes. Embora estas aulas exijam um maior tempo de preparação são também mais fáceis de preparar. Existem várias dificuldades e limitações (parque computacional obsoleto, falta de SE adequado, lacunas técnicas e pedagógicas nesta área), e embora algumas delas estejam a ser vencidas (p.ex. projectos CRIE), considera-se que será premente formar os professores dando-Ihes competências técnicas, mas também pedagógicas, de modo a permitir uma eficaz e real integração desta prática na escola.

Verifica-se que ainda há um longo caminho a percorrer, mas também muita esperança nestes novos métodos: a maioria dos professores que utilizam SE detectou um aumento no aproveitamento dos alunos na disciplina (68\%), na orientação e ajuda recíproca entre eles (79\%) e no interesse pela disciplina (95\%). São estes números que fazem crer que o futuro passa por esta via.

\section{Agradecimentos}

Os autores agradecem a todos os Conselhos Executivos das escolas respondentes e a todos os professores que aceitaram responder ao questionário e a participar na entrevista. Conceição Pedruco agradece todo o auxílio prestado pelo colega Pedro Vidal.

\section{Referências}

[1] Jordi Adell, Tendencias en educación en la sociedad de las tecnologías de la información, 1997 (http://nti.uji.es/ docs/nti/Jordi_Adell_EDUTEC.html, acedido em: 24/11/2006).

[2] Carlos Manuel Delgado Brás, Integração Das Tecnologias da Informação e Comunicação no Ensino da Física e Química. Tese de Mestrado em Educação Multimédia. Faculdade de Ciências - Universidade do Porto, Porto, 2003.

[3] Jacques Delors, A Educação ou a Utopia necessária, (s/data) (http://www.dgidc. min-edu.pt/revista/revista7/jacques_delors.htm, acedido em 24/11/2006).

[4] GEP EDUCAÇÃO, COMPED - Computadores na Educação-primeira fase do IEA, 1993.

[5] Manuela Magalhães Hill e Andrew Hill, Investigação por Questionário, 1. ${ }^{a}$ Edição, Edições Sílabo, Lisboa, 2002.

[6] Anabela Martins, Ana Paula Gravito, Décio R. Martins, Edite M. Fiúza, Isabel Malaquias, M. Manuela F. da Silva, Margarida Neves,Margarida Valadares, Miquelina Mendes, Maria da Conceição Costa, Rolando Soares, Adriano Sampaio, O Livro Branco da Física e da Química, 1. ${ }^{a}$ Edição, Sociedade Portuguesa de Física; Sociedade Portuguesa de Química, Aveiro, 2002.

[7] Maria Margarida O. M. F. Portugal Matos, Trabalho Experimental na Aula de Ciências Físico-Químicas do 3. ${ }^{\circ}$ Ciclo do Ensino Básico: Teorias e Práticas de Professores, Tese de Mestrado em Educação e na Especialidade de Didáctica das Ciências. Departamento de Educação da Faculdade de Ciências - Universidade de Lisboa, Lisboa, 2001.

[8] J. Paiva, As tecnologias de informação e comunicação: utilização pelos professores, 2002. (http://nautilus.fis.uc.pt/ cec/estudo/, acedido em 24/11/2006)

[9] J. Paiva, Ensino do Equilíbrio Químico: subtilezas e simulações computacionais, Tese de Doutoramento em Química, Departamento de Química - Universidade de Aveiro, Aveiro, 2000.

\section{Hidrogénio para reduzir dependência do petróleo}

No dia 20 de Fevereiro os ministros do Ambiente da União Europeia aprovaram um documento, a ser validado no Conselho Europeu agendado para os dias 8 e 9 de Março, que prevê uma redução em 2020 de até 30 por cento, em relação a 1990, dos gases de efeito de estufa.

A queima de combustíveis fósseis é a principal responsável pela emissão de $\mathrm{CO}_{2}$ - que, conjuntamente com o metano $\left(\mathrm{CH}_{4}\right)$, óxidos de azoto $\left(\mathrm{NO}_{\mathrm{x}}\right)$ e clo- rofluorcarbonetos $\left(\mathrm{CF}_{\mathrm{x}} \mathrm{Cl}_{\mathrm{x}}\right)$ constituem os gases de efeito de estufa -, pelo que as metas estabelecidas só serão alcançadas encontrando alternativas energéticas não poluentes.

O hidrogénio já é uma das soluções em que mais se aposta mas o preço elevado de produção é um entrave à sua utilização como combustível alternativo.

Uma equipa do Instituto de Biologia Molecular e Celular da Universidade do Porto (IBMC) integra um projecto europeu que visa a produção limpa e barata de hidrogénio.
O projecto "Engineered Modular Bacterial Photoproduction of Hydrogen - BioModularH2", pretende criar cianobactérias geneticamente modificadas para funcionarem como fotoreactores eficientes de produção de hidrogénio. Este projecto, que integra o Programa de Investigação e Desenvolvimento de Células de Combustível e Hidrogénio da União Europeia, envolve, além do IBMC, a École Polytechnique (França), a Universidad Politecnica de Valência (Espanha), a Uppsala Universitet (Suécia) e a University of Sheffield (Inglaterra). 